\title{
LOS AVATARES FILOSÓFICOS DE LA \\ IMAGEN A PARTIR DEL CINE
}

\section{PHILOSOPHICAL AVATARS OF THE IMAGE THROUGH CINEMA}

\author{
Sergio Aguilera Vita* \\ UNED
}

Resumen: Este artículo explora dos vías filosóficas de acercamiento a las imágenes iniciadas el siglo pasado. La primera, que denominamos metafísica, fue abierta por Bergson y desarrollada por Deleuze. La segunda, que clasificamos como fenomenológica, es iniciada por Sartre y completada por Merleau-Ponty. La posición central que ocupa la imagen en estas teorías permite el desarrollo de una nueva ontología que resuelve los problemas del dualismo y en la que el cine desempeńa un papel principal.

Palabras Clave: Imagen, Cine, Fenomenología, Percepción, Conciencia.

AвsTRACT: This article explores two philosophical pathways for approaching images that were initiated in the last century. The first, which we call metaphysics, was opened up by Bergson and developed by Deleuze. The second, which we classify as phenomenological, was initiated by Sartre and completed by Merleau-Ponty. The central position that the image occupies in these theories makes it possible to develop a new ontology in which cinema plays a main role and which solves the problems of dualism.

KeYwords: Image, Cinema, Phenomenology, Perception, Awareness/Consciousness

* Profesor en Pôle métiers du livre, Université Paris Nanterre. 47 avenue du docteur Arnold Netter, 75012 Paris. E-mail: sergio.aguilera.vita@gmail.com. 


\section{Introducción}

Las primeras imágenes del cinematógrafo aparecen a finales del s. XIX. Al principio, sus posibilidades son consideradas desde el punto de vista de la fotografía, como perfeccionamiento de la técnica por ella iniciada. Con ella y por vez primera en la historia, se captaba la realidad en su verdadera apariencia, sin mediación subjetiva alguna, a diferencia de lo que sucedía en la pintura. El objetivo era "salvar al ser por las apariencias" (Bazin, 2013: 9), según la necesidad básica de la psicología humana que se sitúa en el origen de las artes. Estas operarían una suerte de momificación del ser para salvarlo del devenir. Según el conocido crítico francés André Bazin, podemos leer la historia de las artes como el intento de plasmar la realidad de la manera más realista posible. El cinematógrafo sería entonces el paso definitivo por el cual es captado el devenir. No es casual que la parte del aparato de precisión, la cámara (o, en su caso, el proyector), que permite tal "salvación" se denomine "objetivo", pues se señala así la ausencia de cualquier mediación del sujeto en la captación de lo real (Bazin, 2013: 13). A partir de la fotografía (y del cine), será la naturaleza la que imite la labor del artista y no al revés. Los "cuadros" proporcionados por ella no son captados por la mirada normal. Ejemplos de ello son: la foto de los obreros almorzando en el techo del mundo (Agencia Corbis, 1932), la del beso de los amantes al final de la guerra (Alfred Eisenstaedt, 1945) o el retrato en movimiento del ritmo frenético de la ciudad de San Petersburgo realizado por Dziga Vértov en El hombre de la cámara de 1929. Estas imágenes presentan una realidad aislada del entorno en el que habitualmente se confunde. Funcionan entonces como una suerte de "revelador metafísico" (López Sáenz, 1998: 148) que termina por abolir la distinción lógica entre lo real y lo imaginario (Bazin, 2013: 16). Las artes plásticas, por otro lado, se deshacen del lastre imitativo y la pintura de Cézanne, por ejemplo, se libera de la perspectiva, proporcionando aspectos de lo real que tienen que ver con la mirada propia del artista.

En cualquier caso, las imágenes (visuales y sonoras) que despliega el cine han planteado nuevos retos a la filosofía del siglo XX, obligada desde entonces a repensar la función de la imagen en el pensamiento. Este artículo dará cuenta de dos vías filosóficas de acercamiento ella iniciadas el siglo pasado. La primera, que podemos llamar, a grandes rasgos, "metafísica"; fue abierta originalmente por Bergson y desarrollada posteriormente por Deleuze. La segunda, que clasificaremos de "fenomenológica", fue iniciada por Sartre y completada por Merleau-Ponty. Los cuatro autores han pretendido, con y sin la ayuda del cine, 
pensar las imágenes más allá de las tradiciones dualistas que distinguen la materia del espíritu, el cuerpo del alma, o la naturaleza de la conciencia, y que sitúan la imagen en uno de los dos polos. Veremos que, al profundizar en sus propuestas, las vías inicialmente planteadas se cruzan y se confunden, pues cada autor, a su manera, ha desarrollado formas de pensar que están aún por ser exploradas y que esbozan, lo que podría llamarse, la nueva ontología de la imagen.

\section{La vía metafísica de Bergson}

En 1896, ya Bergson define, en el primer capítulo de Materia y memoria, un universo material formado únicamente por imágenes. Formula esta hipótesis, principalmente, para dar una salida satisfactoria a las contradicciones en las que se ven envueltas las propuestas "dualistas". Estas filosofías no terminan de explicar ni la naturaleza del mundo ni la de nuestras percepciones, ni las representaciones de él ni, por tanto, la naturaleza de las imágenes. Bergson comienza su obra con una afirmación cuanto menos sorprendente que será utilizada años después por Gilles Deleuze para inaugurar otra forma de hacer filosofía a partir de las imágenes de cine:

La materia es para nosotros un conjunto de "imágenes". Y por "imagen" entendemos una cierta existencia que es más de lo que el idealismo llama representación, pero menos de lo que el realismo llama cosa, - una existencia situada a medio camino entre la "cosa" y la "representación" (Bergson, 1965: 5-6).

Entonces, ni los objetos son el producto de nuestras ideas sin existencia separada, ni son en sí tal y como los percibimos. Bergson prefiere considerar el universo como imagen y situar su reflexión en un punto anterior a la disociación que el dualismo ha operado sobre su apariencia. En este universo todas las imágenes reaccionan entre sí en todas sus partes siguiendo las leyes de la naturaleza, de manera que, conociéndolas, podemos predecir su estado futuro, de ahí su definición como "materia". Entre ellas hay, sin embargo, un tipo de imagen que no responde de igual modo al movimiento incesante; se trata del propio cuerpo: 
Mi cuerpo es entonces, en la totalidad del mundo material, una imagen que reacciona como las otras imágenes, recibiendo y devolviendo movimiento, quizás con una sola diferencia, que mi cuerpo parece elegir, en cierta medida, la forma de devolver lo que recibe (Bergson, 1965: 12).

Mientras que el resto de las imágenes reflejan inmediatamente todo su entorno, esta imagen viva demora su repuesta, escogiéndola entre las posibles. Mediante la percepción, el cuerpo mide la acción virtual que puede llevar a cabo sobre el resto de las imágenes. Este termina reflejando sólo lo que le interesa en función de su adaptación y supervivencia. Este reflejo constituye la acción del cuerpo. El resto no reflejado es absorbido constituyendo su parte afectiva. La afección, dice Bergson, consiste en la acción real de las imágenes-cosas sobre el cuerpo. Respecto a la percepción del cuerpo, la afección es «la impureza que se mezcla con ella» porque «no hay percepción sin afección» (Bergson, 1965: 33).

Hay que tener en cuenta que percepciones y afecciones se producen en función de la (re)acción del cuerpo ante las imágenes, por lo que es inútil considerarlas como la base del pensamiento especulativo, como hacen las concepciones tradicionales de la filosofía y la psicología. Estas han tomado la afección, a la que llaman "sensación", como materia primera de la percepción. Se han visto entonces obligados a establecer una diferencia de grados entre el carácter inextenso de la afección y el estado extenso de la percepción, convertida ahora en representación; o a postular algún tipo de síntesis por la que a partir de sensaciones puedan darse percepciones. Su error se debe al desconocimiento de la naturaleza de las funciones corporales asociadas a la percepción y a la afección.

La especialización de los órganos corporales es fruto de la evolución: «En un organismo como el nuestro, las fibras sensitivas se encargan exclusivamente de transmitir las excitaciones a una región central que difundirá la sacudida a los elementos motores» (Bergson, 1965: 32). Nada hay de inextenso en la afección, siempre localizada en el interior del cuerpo y originada en un órgano receptor que tiene cortada su salida hacia los órganos motores.

En su interacción con el mundo, el cuerpo ha evolucionado a conveniencia, ha sido "educado" para retener y reaccionar de una determinada manera ante las imágenes. Por eso, no tiene acceso directo al movimiento de estas sino mediado por la selección que hace de ellas. La conciencia o inteligencia solo alcanza a 
captar instantáneas de la realidad, sin dar cuenta en ningún caso de su movimiento o duración real. Nuestras percepciones sucesivas de las cosas no son entonces momentos reales de estas, sino de nuestra conciencia. Su función teórica es la de unir las percepciones sirviéndose de la memoria. Es por su causa que las reacciones de nuestro cuerpo son indeterminadas, pues están mediatizadas por todo lo aprendido. Sin embargo, este pasado recordado no tiene un origen diferente de las percepciones mismas, ya que está formado por percepciones retenidas por el cuerpo en función de su utilidad para la vida. No existe, entonces, la percepción pura, «percibir no es más que una ocasión para recordar» (Bergson, 1965: 38).

Resumiendo, percepción, afección y memoria, son funciones de esta imagen especial que es el cuerpo, que siempre está listo para reaccionar ante las imágenes en movimiento que constituyen el universo. Por su emplazamiento real en él como una imagen más, el cuerpo tiene la posibilidad de acercarnos a las cosas de manera que podamos conocerlas tal y como son en sí mismas, sin confundirlas con el conocimiento que tenemos de ellas.

Cuando Bergson planteaba este universo de imágenes, el cinematógrafo acababa de nacer y se explotaba como mera atracción de feria. El cine narrativo aún estaba por inventarse. Probablemente la ignorancia de las posibilidades del aparato, explotadas más tarde mediante la técnica del montaje, llevó a Bergson a comparar su funcionamiento con el de la conciencia abstracta. En el capítulo cuarto de La evolución creadora de 1907, el filósofo vitalista sostiene que aparato y conciencia prestan un movimiento artificial a las imágenes inmóviles reconstruyendo su duración real de forma mecánica: «En lugar de ensamblarnos con el devenir interior de las cosas, nos sitúa fuera de ellas para recomponerlo artificialmente» (Bergson, 1959: 179). Para Deleuze en cambio, como veremos más tarde, las imágenes materiales y en constante movimiento que forman el universo de Materia y memoria, son las imágenes del cine. Se presenta allí «el universo como cine en sí, como "metacine”» (Deleuze, 1983: 88).

\section{La evolución de la imagen en Deleuze}

La preocupación de Deleuze por la imagen es, sin embargo, anterior a la apropiación crítica que hará de las teorías de Bergson en sus estudios sobre el cine. En su obra Diferencia y repetición de 1968, habla de las imágenes como base del pensamiento filosófico. Sostiene entonces que la filosofía no es capaz de 
operar y definirse sin darse una imagen de sí misma, «no hablamos de tal o cual imagen del pensamiento variable según los filósofos, sino de una sola Imagen en general que constituye el presupuesto subjetivo de la filosofía en su conjunto» (Deleuze, 1993: 172). Esta imagen del pensamiento tiene como presupuestos implícitos la existencia de un sentido común y la creencia en la buena voluntad del pensamiento, que siempre buscaría la verdad. Con estos presupuestos, la imagen valida el modelo del pensar como reconocimiento. Pensar es entonces representarse realidades ya imaginadas de manera implícita. El pensamiento trataría de rescatarlas de un fondo pre-filosófico, aún impensado de manera objetiva y que construiría algo así como el suelo del que se nutre toda filosofía posterior.

Una orientación así es desafortunada para la filosofía. Porque el triple nivel supuesto de un pensamiento naturalmente recto, de un sentido común natural, del reconocimiento como modelo trascendental, no puede constituir más que un ideal de ortodoxia. La filosofía no tiene así ningún medio de realizar su proyecto que era el de acabar con la doxa (Deleuze, 1993: 175).

Toda la filosofía tradicional sería producto de esa imagen cuya culminación es el sujeto cartesiano, kantiano o fenomenológico. Capaz de abstraerse de las circunstancias que lo envuelven y, por tanto, siempre idéntico a sí mismo, este sujeto daría origen al pensamiento funcionando como un espejo que reflejaría, duplicándolo, todo lo real. La dificultad de estas filosofías reside en dar una explicación satisfactoria tanto del espejo o sujeto idéntico y su funcionamiento, como de la correspondencia del reflejo mismo con la realidad reflejada. En esta problemática se ha movido la filosofía generando las propuestas materialistas, realistas, espiritualistas o idealistas que ya fueron denunciadas por Bergson. Para Deleuze, todas ellas son un ejemplo de la anti-filosofía, precisamente por partir de presupuestos no explicitados. Lo que él propone en Diferencia y repetición, como auténtico proceder filosófico, es un pensar sin imagen, no sumiso al reino del reconocimiento o de la representación y apartado de las formas del "buen" pensamiento. En este pensar el primado de la identidad deja paso al de los simulacros, pues todas las identidades son un efecto óptico producido por el juego más profundo de la diferencia y la repetición (Deleuze, 1993: 1). En esta suerte de empirismo deleuziano, las distinciones tradicionales no sirven, «los conceptos 
son las cosas mismas, pero las cosas en estado libre y salvaje más allá de los "predicados antropológicos"» (Deleuze, 1993: 3). Lo que se impone entonces es una práctica de la Repetición que resalte la Diferencia, es decir, ese aspecto de las cosas nunca pensado en filosofía. Se trata violentar el pensamiento pues, lejos de ser algo reconfortante, el pensar es siempre violento "y nada supone que la filosofía no sea más bien una "misosofía”" (Deleuze, 1993: 181-182).

Esta forma de pensamiento sin imagen va a consolidarse años más tarde en la noción de "plano de inmanencia", donde se constituye la verdadera topología del pensar deleuziano. El plano de inmanencia es un corte en el caos de materia, es variación de ella, y cada filósofo procede con su teorización desde el suyo propio. La filosofía es ahora "[...] el arte de formar, de inventar, de fabricar conceptos" (Deleuze, 2013: 6) a partir de estos planos o cortes, que podrían definirse como imágenes del pensamiento. «Es en este paso de una imagen del pensamiento como correlato de las malas filosofías a la imagen del pensamiento como instauración de toda filosofía, que interviene el cine» (Hême de Lacotte, 2007: 126). El plano de inmanencia está compuesto por lo que aún no ha sido pensado pero que origina el pensamiento. Es un suelo pre-racional, no compartimentado conceptualmente que funciona como una suerte de automatismo discursivo en el que cada cosa remite al resto, al modo del universo imágenes que Bergson describía en Materia y memoria y que Deleuze reconoce como "universo cinematográfico". La ventaja del cine es la de ofrecer la imagen del pensamiento (o el plano de inmanencia) en su movimiento propio, sin centros subjetivos ni objetivos que la distorsionen.

En efecto, en el capítulo cuarto su primera obra sobre cine, Deleuze retoma aquellas imágenes-materia que Bergson proponía para evitar el enfrentamiento entre materialismo-idealismo. Movimiento e imagen son la materia del universo que "constituye una suerte de plano de inmanencia» (Deleuze, 1983: 86). Este

[...] es un conjunto, pero un conjunto infinito: el plano de inmanencia es el movimiento (la cara del movimiento) que se establece entre las partes de cada sistema y de un sistema a otro, que los atraviesa a todos, los agita y los somete a la condición que les impide ser absolutamente cerrados (Ibídem: 87). 
Para Deleuze este es el universo concebido como cine en sí, compuesto en su totalidad de imágenes que se suceden y reaccionan entre sí de manera inmediata, y a partir del cual se da todo lo demás. En él hay imágenes-movimiento, es decir, cortes móviles de la duración o el todo (planos), a partir de cuyo montaje, el cine ofrece una imagen indirecta del tiempo. También hay imágenes-tiempo que muestran directamente la duración sin referencia al movimiento, además de «imágenes-cambio, imágenes-relación, imágenes-volumen [...]» (Deleuze, 1983: 22).

En sus estudios de cine, Deleuze reconoce, además del de Bergson, otro intento de superar la crisis en la que la psicología asociacionista se hallaba inmersa a finales del S.XIX, el de la fenomenología. Sin embargo, Deleuze señala una diferencia fundamental que le hace decantarse por Bergson. Si la innovación de la fenomenología puede resumirse en la intencionalidad o en la afirmación de que "toda conciencia es conciencia de algo", la del bergsonismo puede sintetizarse diciendo que "toda conciencia es algo" (Deleuze, 1983: 84). Es verdad que, a partir del señalamiento del carácter intencional de la conciencia, la fenomenología anula la separación entre los ámbitos subjetivo y objetivo, destacando la importancia de la relación que los une. Sin embargo, la constitución de la objetividad sigue dependiendo, según Deleuze, de las condiciones de aprehensión del sujeto, principalmente de la percepción natural. Habría que atenerse a sus condiciones, cosa que el cine no hace, para comprender la naturaleza de las imágenes. Desde la propuesta de Bergson, en cambio, las imágenes son lo prioritario, siendo la conciencia un tipo de imagen más, compuesta a partir de otras imágenes: imagen-percepción, imagen-afección, imagen-acción, todas imágenes-movimiento o cortes móviles del devenir.

\section{La fenomenología de la imagen en Sartre}

Llamamos metafísicas a las propuestas de Bergson y Deleuze porque en ellas el universo es imagen y se expresa por imágenes. La ontología que dibujan emborrona, no sólo la división clásica entre las facultades, sino también la distinción misma entre sujeto y objeto. Es esta indistinción, que termina identificando la percepción con la imagen, lo que preocupará a Sartre a la hora de llevar a cabo sus estudios sobre la segunda, probablemente los más completos y extensos dedicados al tema del pasado siglo. En sus dos libros, Limagination de 1936 y L'imaginaire de 1940, intenta resolver los problemas del clasicismo en su intento 
de explicación de la percepción y de la imaginación. Lo hace a partir de las descripciones de Husserl del funcionamiento de la conciencia como intencionalidad. La conciencia es competente para reconocer la naturaleza de los objetos porque aparece siempre en relación intencional con ellos. En esta relación, el acto de conciencia actúa como un todo estructurado con aquello a lo que remite. Se trataría entonces de reconocer si esta relación es de carácter perceptivo o imaginativo. Señalemos, en todo caso, que la afirmación fenomenológica de que toda conciencia es intencional no debería implicar una recaída en el subjetivismo, sino propiciar una comprensión no escindida de lo real; tal es el objetivo de la intencionalidad fenomenológica.

L'imagination recorre las concepciones de la imagen hasta la aparición de la fenomenología, criticándolas ferozmente. Sartre las denomina "metafísicas u ontologías ingenuas", porque confunden la esencia de la imagen con la de su objeto, complicando así con la teoría una distinción que hacemos sin confusión de forma espontánea. Por ejemplo, la hoja de papel que hace un momento tenía delante de mí guarda efectivamente una relación de identidad con la imagen que conservo de ella ahora que no la veo, «sólo que esa identidad de esencia no va acompañada de una identidad de existencia» (Sartre, 1967: 8). Esta última existe en imagen y «no se impone como un límite a mi espontaneidad» (Ídem), como si sucede con las cosas que mi conciencia percibe como tales. Estas concepciones tratan la imagen como un objeto existente o cosa que afecta a la conciencia, que queda así sujeta a la facticidad, lo que hace imposible la elaboración de una teoría coherente sobre sus funciones, la de imaginar o la de percibir, y productos, lo imaginario o lo perceptivo. El germen de estas metafísicas se encuentra ya en los tres autores clásicos analizados por Sartre en el primer capítulo de su libro. Se trata de Descartes, para el que la imagen tiene una función mecánica, lo que la aparta del pensamiento; Hume, quién reduce el pensamiento a asociaciones, también mecánicas, entre imágenes; y Leibniz para el que la imagen, tomada como signo, da lugar a un pensamiento que no puede explicarse por sí mismo. En sendas concepciones, a la imagen se la sitúa en el lado de la sensibilidad por lo que termina siendo una percepción disminuida imposible distinguirla en esencia de la percepción misma. Los intentos de la psicología del XIX de aclarar el estatuto de la imagen son fruto de la atmósfera positivista que impregnaba el pensamiento y se quedan en revisiones y reelaboraciones de los tres paradigmas señalados. Lo fisiológico se confunde con lo psicológico y la conciencia aparece como producto final de movimientos mecánicos. 
Es el advenimiento del psicologismo que [...] no es más que una antropología positiva, es decir, una ciencia que quiere tratar al hombre como como a un ser en el mundo, descuidando este hecho esencial: que el hombre es también un ser que se representa el mundo y a él mismo en el mundo (Ibídem: 21).

De todos los intentos surgidos de esta atmósfera destaca Sartre el de Bergson que, al igual que él, trata de combatir las concepciones asociacionistas que convierten la imagen y la conciencia en cosas. Sin embargo, su metafísica basada en la materialidad de la imagen y su concepción de la conciencia como duraciónintervalo, no resiste la crítica sartreana. La imagen está, otra vez, cosificada y lo que «encontramos en el fondo de estas teorías engańosas [es] la simple afirmación de los empiristas: la imagen y la percepción no difieren en naturaleza, sino solamente en grado» (Ibídem: 50). Más allá de lo adecuado de la crítica, lo que Sartre no ve en Bergson es de qué manera puede posicionarse coherentemente una conciencia espontánea en el universo mecánico de imágenes propuesto. Porque Sartre parte, en el estudio de la imagen, de la distinción neta entre conciencia y mundo o, formulado en términos sartreanos, entre dos tipos de existencia, una en sí y otra para sí. Existen en sí las cosas o el mundo que yo puedo percibir, con los que cuento y con los que actúo, siempre dentro de los límites que me imponen. Cosas y mundo se me presentan como pura inercia. La existencia para si es, en cambio, la de mi conciencia, pura espontaneidad que no se impone límites, sino que los encuentra fuera de ella. La solución del problema de la imagen la encuentra Sartre finalmente en Husserl y su fenomenología. "En las Ideen se encuentran las bases de una teoría de las imágenes enteramente nueva» (Ibídem: 115). El reconocimiento de la estructura intencional de la conciencia permite, según él, la separación entre esta y el mundo al que está dirigida. «La imagen también es imagen de algo. Nos encontramos, pues, con una referencia intencional de una cierta conciencia a cierto objeto» (Ibídem: 117). Así, la diferencia entre percepción e imagen viene dada por la intención diferente que tiene la conciencia al referirse a las cosas. Esta "intenciona" de forma pasiva en la percepción y activa en la imagen, siendo el objeto de ambas siempre y en cualquier caso un trascendente.

Así lo expresa en L'imaginaire, obra aparecida cuatro años después. En la primera parte del libro (Le certain), describe fenomenológicamente la imagen distinguiéndola de la percepción. La confusión entre aquella y esta, propiciada por 
la psicología y el empirismo que entienden la primera como una copia debilitada de la segunda, viene de lo que el autor denomina ilusión de inmanencia, debida a nuestra costumbre de pensar en términos de espacio. La tendencia a incurrir en este error es la que nos hace comprender la imagen como objeto, como una especie de simulacro de lo representado por ella que, de este modo, podía penetrar en nuestra conciencia a modo de percepción debilitada. Sin embargo, desde la perspectiva sartreana, no es que la conciencia pueda aprehender imágenes en lugar de objetos, sino que la imagen es una manera que tiene la conciencia de darse directamente los objetos, una manera que podemos llamar "imaginante". Lo que explicaría la pobreza esencial de la imagen, su aspecto de percepción débil se debe a que el saber sobre aquella está ya constituido por la conciencia. La hoja de papel de la que hablábamos más arriba dada a la percepción es inagotable, multiplica al infinito su forma y color, dependiendo de la perspectiva, de la incidencia de la luz en ella, de su distancia con las cosas que la rodean. En cambio, en imagen, tiene una forma, color y textura determinados y guarda ciertas relaciones con ciertos objetos de alrededor, todas ella explicitables de un golpe. Inútil explorar más allá esta imagen para encontrar algo que no esté ya dado en la conciencia. Según Sartre, se da en la imagen una síntesis entre un saber ya adquirido y una intención de (re)presentarlo. Por eso, «nuestra actitud en relación con el objeto imaginado podría llamarse "casi-observación"» (Sartre, 2013: 28), ya que de ella nada nuevo se aprende. Finalmente, sostiene el fenomenólogo que el objeto de la imagen no está o no es; es nada, a diferencia del objeto de la percepción que se impone a la conciencia como algo que tiene existencia efectiva. En la imagen, es la conciencia la que crea su objeto, de ahí la aparición en ella de diferentes puntos de vista inconciliables sobre él, que lo hacen impreciso y vago en comparación con el objeto realmente percibido.

Para explicar de qué manera en la conciencia puede darse la presencia de una ausencia, Sartre va a tomar prestada la noción husserliana del "análogo". Se llama así a la materia que necesita la conciencia para hacer aparecer la cosa en imagen cuando no puede percibirla. Una fotografía o una caricatura de Pedro, por ejemplo, poseen en sí una materialidad, se trata de un tipo de papel impregnado de ciertas formas y colores. Cuando nuestra conciencia imagina a partir de este material, aparece el objeto representado, o sea Pedro y no la fotografía misma. De igual modo, en la interpretación actoral, los gestos sirven de análogo material del personaje representado y, dependiendo del tipo intención que la conciencia les dirija, imaginamos el personaje o percibimos el actor. «El análogo es, entonces, lo que asegura la dimensión de presencia en lo imaginario» (Colonna, 2003:119). A partir de la distinción, también tomada de Husserl, entre trascendencia y 
exterioridad, Sartre puede decir ahora que «es la cosa representada la que es exterior, no su "análogo" mental. La ilusión de inmanencia consiste en transferir al contenido psíquico trascendente la exterioridad, la espacialidad y todas las cualidades sensibles de la cosa» (Sartre, 2013: 110). Queda explicada de esta manera, la creencia en la realidad del objeto que suscita la imagen, que se manifiesta en la aparente pasividad de la conciencia ante ella; "aparente" porque la conciencia, en realidad, es activa y la imaginación un acto de la conciencia.

Pese a la devoción hacia Husserl, expresada en los dos libros, pensamos que la teoría de la imagen de Sartre termina traicionando su fenomenología. Mientras que en el primero la propone como único enfoque válido para resolver los problemas en torno a la imagen, en el segundo lleva a cabo una lectura interesada de ciertas nociones del maestro ${ }^{1}$, al que cita apenas siete veces en sus más de trescientas páginas, y asume en cambio, aspectos polémicos de su teoría ${ }^{2}$. Lo que Husserl ha conseguido, a pesar de Sartre, es «aproximar la imaginación a la percepción de tres maneras» (Coorebyter, 2012: 24): se trata en ambos casos de actos intencionales que pueden, además, tener la misma materia y, lo más importante, que se conciben como modalidades de la intuición que aportan información a la conciencia sin mediaciones, pues ni la imagen ni por supuesto la percepción, funcionan en Husserl como signos. No hay una ruptura radical en él entre imagen y percepción, «al contrario, las inscribe en el registro de la búsqueda de plenitud, de la voluntad de considerar el objeto en su singularidad, sin realmente mostrar en qué punto [...] contrastan y se oponen» (Coorebyter, 2012: 25). Aunque la intención de la imagen termine proponiendo, como en Sartre, la nada o lo no existente, la imagen queda sujeta en Husserl a la percepción, completando las carencias de esta en su aprehensión de la realidad. Sartre insiste en cambio, en la separación radical de ambos actos intencionales. Con ello, acentúa la distancia entre la conciencia y el mundo salvaguardado, eso sí, las virtudes creativas de aquella frente a la reproducción de la percepción.

Desde este punto de vista, el cine, como todo arte figurativo, sería creación espontánea de la conciencia. Las imágenes desplegadas en la pantalla servirían de materia analógica para las conciencias imaginativas de los espectadores. Las diferentes secuencias y planos, la interpretación de los actores, las músicas y

1 Las nociones vistas de analogon, trascendencia y exterioridad.

2 Nos referimos al hilemorfismo, muy criticado en Husserl, en la explicación de la imagen a partir del análogo material al que informaría (intencionalmente) la conciencia. Véase al respecto Colonna, 2003: 118. 
sonidos constituirían el imaginario de los autores del film. Ningún saber sobre el mundo se desprendería de las películas ni sería posible articular en ellas una ontología. Sin embargo, Sartre nada dice del cine en estas obras. Tenemos que buscar mucho antes, en 1924-1925, en un artículo titulado "Apologie pour le cinema. Défense et illustration d'un Art international', sus opiniones sobre el séptimo arte. Sartre defiende allí el cine como arte del movimiento contra Alain y a favor de Bergson. El primero consideraba que el verdadero arte expresa su potencia por la inmovilidad ${ }^{3}$ mientras que Sartre, apoyándose en Bergson, defiende el cine como arte de lo móvil y habla de una nueva estética que va a destronar la de las ideas platónicas 4 . En la sala de cine, dice, somos conducidos por la película a otra realidad, "sumergidos en esa noche que los poetas alemanes celebraban como el Ser». La movilidad y la duración crean el ritmo de la película como si de una sinfonía organizada se tratara. Poema moderno, esta es un conjunto inseparable que tiene virtudes medicinales para la conciencia, «nos hace pasar de la objetividad absoluta a la pura subjetividad» (Sartre, 1990: 397). Por todo, «el film mismo es una conciencia» (Ibídem: 390). Concluye Sartre sosteniendo que el cine es el signo de los tiempos que corren, en franca ruptura con los anteriores por su concepción del arte, de la estética y del saber en general.

\section{Cine, percepción e imagen carnales en Merleau-Ponty}

No sólo la defensa del cine a partir de la lectura de Bergson haría de Sartre un precedente de Deleuze ${ }^{5}$, sino que una lectura interesada de este pequeño artículo nos llevaría a ver en él el esbozo de la conferencia que Merleau-Ponty impartió en el IDHEC veinte años después. En ella explicaba las ventajas de la nueva psicología de la Gestalt para entender la percepción. Contrariamente a la vieja escuela, la nueva psicología no concibe las sensaciones como material para formar percepciones que se harían presentes sólo al entendimiento: «la percepción de formas [...] debe ser considerada como nuestro modo de percepción espontáneo» (Merleau-Ponty, 1996: 63). No se percibe por adición de elementos o asociación de sensaciones, sino globalmente y con todos los sentidos a la vez, haciendo funcionar una especie de sentido general. Por eso en la percepción contamos

\footnotetext{
3 «El arte expresa la potencia humana por lo inmóvil. No hay mejor signo de la fuerza del alma que lo inmóvil, desde que lo reconoce el pensamiento» (Alain, 1949: 14).

4 Sobre la recaída de Sartre en el "platonismo" de Alain léase: Colonna 2003, p. 118-119.

5 Carbone, 2016: 13.
} 
incluso con aquello que tenemos a la espalda o que queda oculto por las figuras que se encuentran en un primer término. La imagen de la melodía, que también utiliza Merleau-Ponty en el artículo, es muy ilustrativa. Ella se escucha como un todo y no como yuxtaposición de elementos o notas, las cuales sólo valen en relación con el conjunto.

Pues bien, el film es también una totalidad, una forma completa y temporal como la melodía, no simple suma de imágenes. El sentido de cada imagen viene de la anterior y se recoge en la posterior componiéndose al final un todo que no es mera suma de sus partes. Un mundo se organiza delante de mí en la película sin tener que pensarlo, como sucede en la percepción de la realidad. Así, percibimos los elementos que componen el film (luz, color, sonido...), no de manera aislada, sino ofreciéndonos sentido. Es el autor quien compone, con los emblemas sensibles de una idea los hechos a narrar, el film como monograma visible y sonoro. Sin embargo, su función no es exponer ideas o hechos, sino expresar realidades, como hace el arte. La literatura o la poesía, también el cine, lo son, no por lo que cuentan, sino por la elección de lo que muestran y el modo como lo hacen, por su composición original del "tempo" variable de la narración. De esta manera, la obra artística adquiere unidad y no hay posibilidad de separar en ella lo que se cuenta de la forma cómo se cuenta. La nueva psicología y el cine comportan ambos una revolución del saber (Merleau-Ponty, 1996: 75). Este no va a consistir ahora en analizar realidades para sintetizarlas después produciendo una escisión en el seno de la realidad misma. No se trata de separar la sensación del entendimiento, el contenido de la forma, la materia del espíritu, sino de describir la realidad tal y como se presenta, porque es en esa presentación global donde se configura y reside el contacto primigenio con ella y todo análisis analítico es posterior y lo supone.

La percepción, ya lo vimos también con Sartre, es siempre ambigua, deja un fondo sin explorar que nunca se agota, por mucho que cambiemos de perspectiva. Sin embargo, la perspectiva no la deforma subjetivamente alejándonos de las cosas en sí, sino que es en verdad lo que las constituye. Por ella entendemos que hay una realidad independiente que no se confunde con lo que captamos de ella en cada momento, sino que se escapa siempre a nuestra conciencia. Es lo que Sartre denomina el ser en-sí y que termina oponiendo al ser para-sí o conciencia. Merleau-Ponty sostendrá en cambio que es en el posicionamiento del propio cuerpo donde se resuelve la perspectiva que constituye esencialmente toda percepción. A nivel corporal, la relación unitaria del ser humano con el mundo no ha sido aún quebrada, esto lo hará después la reflexión concibiendo el cuerpo 
como la máquina inerte que pilotará la conciencia para dirigirlo a las cosas. Porque hay un cuerpo, objeto y sujeto son coextensivos. En realidad, este «vive en un universo de experiencia, en un medio neutro a las distinciones sustanciales entre el organismo, el pensamiento y lo extenso, en un comercio directo con los seres» (Merleau-Ponty, 1967: 204).

Ese medio neutro viene dado por el funcionamiento perceptivo-motor del propio cuerpo al ser solicitado por las cosas y proyectarse hacia ellas. La motricidad es la esfera primaria donde se engendran todas las significaciones. Estas se producen al habituarse el cuerpo al medio que le requiere. Mediante este posicionamiento motor y perceptivo aparece el mundo como entidad con sentido. El cuerpo se ancla en el mundo y al hacerlo, delimita un entorno de significatividad en el que no hay sujeto de determinaciones absolutas, pero que permite un tratamiento intersubjetivo. Es en la misma existencia donde se ancla nuestro cuerpo y el del otro, donde produce para ambos la fundación activa del significado (Stiftung) y donde cada uno expresa su propio estilo. El cuerpo en esto funciona como las obras de arte, que expresan la vivencia que se tiene de la realidad sin tratar de representarla. Como la obra, también el cuerpo es mezcla «de lo imaginario y de lo real, de lo invisible y de lo visible, de la forma y de la materia" (López Sáenz, 2003: 168). En la obra de arte se plasma claramente el carácter creativo de toda percepción. Hay un estilo del mundo, dice Merleau-Ponty, y es definido por el arte. El estilo corporal procede de la habituación del cuerpo, de su anclaje en el mundo, y concierne a todas las dimensiones vivenciales «en su dinámica, porque actúa como modelo generativo e interpretativo de toda comprensión y de toda imagen de sí y de lo otro» (Ídem). Por el estilo que comporta, "no es al objeto físico a lo que puede compararse el cuerpo, sino más bien a la obra de arte» (Merleau-Ponty, 1945: 176).

Como toda la expresividad corporal viene subtenida en su unidad vivencial, que imprime dirección a sentidos, sentimientos, intelecciones, etcétera, es posible asignar una función a la imagen al lado de la percepción y no subordinada a ella, que es como se la ha venido entendiendo en el tratamiento que hace la filosofía de la imaginación. La imagen no es copia débil de la percepción, sino que comporta un componente creativo. Imagen y percepción se complementan, pues el carácter inacabado de la percepción, que es producto del punto de vista proporcionado por el anclaje del cuerpo al mundo, se ve enriquecido mediante la producción de imágenes. Estas pierden la perspectiva intersubjetiva que sí daba la percepción, pero su carácter icónico las sitúa más cerca que el signo lingüístico del ámbito pre-objetivo definido por la percepción. «Gracias a sus 
poderes de irrealización, la imaginación se mueve en lo absoluto, mientras que la percepción se sabe parcial» (López Sáenz, 2003: 162). Este movimiento hacia lo absoluto de la imaginación permite el tratamiento de la cara invisible de lo visible, favoreciendo la génesis del sentido. Pues para Merleau-Ponty, las estructuras perceptivo-motoras que engloban al cuerpo y al mundo revelan un tejido que constituye la carne del mundo (Chair). Ese suelo pre-objetivo al que accedemos mediante la percepción, previo a toda determinación, donde se resuelven perceptor y percibido, forma una región del ser. En ella quedan relacionados los elementos de lo real de tal manera que permiten la lectura de un sentido. Una de esas relaciones es la reversibilidad entre polos perceptivos, entre el vidente y lo visible. Podemos apreciar en la obra de arte una muestra de esta reversibilidad cuando, por ejemplo, el pintor estiliza lo real en su composición pictórica llegando más lejos que la mirada normal. Parece que es el mismo objeto en su expresividad el que dirige la mirada del artista siendo este, además de sujeto de percepción, objeto también de ella.

Para Merleau-Ponty, la obra de arte propicia el desocultamiento del ser ofreciéndonos verdad. Desvela «un aspecto de lo pre-real que fundamenta toda realidad y reactiva en nosotros la fuerza de la imaginación y el deseo» (López Sáenz, 1998: 148). Es así porque lo que propone la obra no se considera como el sólo fruto de una subjetividad, sino que implica a la estructura carnal del mundo $y$, por eso, tiende puentes de sentido que se activan de forma creativa en otros sujetos. La mirada del artista es capaz de atender, no sólo a la horizontalidad del ser, sino también a su verticalidad. El uso normal de la mirada se queda en la superficie de las cosas, reteniendo aquello que sirve a su practicidad. La mirada del artista, en cambio, accede al interior del objeto, a un nivel más profundo de su existencia que el de su mera representación, y consigue plasmarlo en la obra. De ahí las esculturas de Giacometti o de Botero, que evocan en el espectador sentidos múltiples e inagotables sobre el movimiento, el tiempo y el espacio, la gravidez o la expresividad corporal. 


\section{Conclusión}

En esta caracterización de la obra de arte hemos hecho referencia a la última filosofía de Merleau-Ponty donde esta adquiría un sesgo marcadamente ontológico. El concepto de carne (Chair) termina ahora de desligar el ámbito perceptivo del sujeto, extendiendo la noción de estructura a la presentación misma del ser. Un famoso pasaje de su obra tardía, El ojo y el espiritu, lo aclara de una forma bella y concisa:

Visible y móvil, mi cuerpo está entre las cosas, es una de ellas, está preso en el tejido del mundo y su cohesión es la de una cosa. Pero, como ve y se mueve, tiene las cosas en círculo alrededor de sí, ellas son un anexo o prolongación de él, están incrustadas en su carne, forman parte de su definición plena y el mundo está hecho de la misma tela del cuerpo (Merleau-Ponty, 1964: 19).

En esa tela carnal que envuelve al mundo ya no hay centros que dirijan la percepción, pues el cuerpo que instaura la visibilidad se hace visible con las cosas que pasan a pertenecer a esa estructura corporeizada, a estar entrelazadas con él.

Nuestra tesis es que, igual que el bastón que usa el ciego amplía su visión y no es vivido como apéndice sino como cuerpo propio extendido, las imágenes del film son asimiladas por el cuerpo como extensión de su percepción, definiendo una realidad más rica en la que ambos, cuerpo e imagen, están imbricados. El cine se compone de imagen y movimiento, ambos elementos claves para dibujar la corporeidad del mundo donde se origina y renueva toda significación. La potencia simbólica que poseen la visión y el movimiento permite al cine mostrar, a partir de ambos, la riqueza perceptiva de la carne del mundo. Quizá venga de ahí la fascinación que produce, el choque que, según Deleuze, genera en el pensamiento alimentándolo. Al fin y al cabo, en el film se pone en marcha la misma estructura perceptiva de la que surge toda significación, lo que permite su tratamiento, desde la fenomenología ontológica Merleau-Ponty, como forma corporal capaz acceder a la verticalidad del Ser. 


\section{Bibliografía}

Alain, Émile Chartier (1941). "L'immobile". Propos sur l'esthétique. Paris, PUF. pp. 14-15 (edición electrónica de la Université du Québec à Chicoutimi).

Bergson, Henri (1959). L'évolution creatrice. Paris, PUF (edición electrónica de la Université du Québec à Chicoutimi).

- (1965). Matière et mémoire. Paris, PUF (edición electrónica de la Université du Québec à Chicoutimi).

- (1968). Durée et simultanéité, à propos de la théorie d'Einstein. Paris, PUF (edición electrónica de la Université du Québec à Chicoutimi).

BAZIN, André (2013). "Ontologie de l'image photographique". Qu'est-ce le cinema. Paris, Les éditions du Cerf, pp. 9-18.

Carbone, Mauro (2016). Philosophie-Écrans. Du cinema à la revolution numérique. Paris, VRIN.

Colonna, Fabrice (2003). "Merleau-Ponty penseur de l'imaginaire". Ed. R. Barbaras, M. Carbone, L. Lawlor. Chiasmi International 5, Le réel et l'imaginaire. Paris, VRIN, pp. 111-144.

Coorebyter, Vincent de (2012). "De Husserl à Sartre. La structure intentionnelle de l'image dans L'Imagination et L'Imaginaire", Methodos 12 [En ligne]. Mis en ligne le 28 mars 2012, consulté le 10 juillet 2017. URL: http://methodos.revues.org/2971; DOI: $10.4000 /$ methodos.2971

Deleuze, Gilles (1993). Différence et répétition. París, PUF.

- (1983). Cinéma 1. L’image-mouvement. Paris, Les éditions de minuit.

- (1987). La Imagen-tiempo. Estudios sobre cine 2. Barcelona, Paidós.

- (2013). Qu'est-ce que la philosophie? Paris, Les éditions de minuit (édition électronique).

Hême de LaCotte, SuZAnne (2007/2). “Image cinématographique et image de la pensée philosophique”. Chimères ( $\left.\mathrm{N}^{\circ} 64\right)$, pp. 117-129.

López Sáenz, Ma Carmen (2003). "La imaginación carnal en Merleau-Ponty". Revista de filosofía 28 (1), pp. 157-169.

- (1998). Merleau-Ponty y el arte de la visibilidad. Ágora, Papeles de Filosofía, 17 (2), pp. 145-165.

Merleau-Ponty, Maurice (1945). Phénoménologie de la perception. Paris, La librairie Gallimard, (edición electrónica de la Université du Québec à Chicoutimi).

- (1964). L'oeil et l'esprit. Paris, Éditions Gallimard (edición electrónica de la Université du Québec à Chicoutimi).

ÉNDOXA: Series Filosóficas, n. ${ }^{\circ}$ 43, 2019, pp. 293 -311. UNED, Madrid 
- (1967). La structure du comportament. Paris, PUF, (edición electrónica de la Université du Québec à Chicoutimi).

- (1996). "Le cinema et la nouvelle psychologie". Sens et non-sens, Paris, Édition Gallimard, pp. 61-75.

Sartre, Jean Paul (1967). La imaginación. Buenos Aires, Editorial Sudamericana.

- (2013). L'imaginaire. Paris, Éditions Gallimard.

- (1990). "Apologie pour le cinema. Défense et illustration d'un Art international", Écrits de jeneuse. Paris, NRF Gallimard, pp. 385-405.

Recibido: $27 / 08 / 2017$

Aceptado: 16/10/2017

Este trabajo se encuentra bajo una licencia de Creative Commons ReconocimientoNoComercial-SinObraDerivada 4.0 
